\title{
Synthesis of Novel Organogermanium Derivative Conjugated with Vitamin C and Study of its Antioxidant Effects
}

\author{
Doo Hyeon Lim, Minghua Li, Eun-hye Kim, and Seung Wook Ham* \\ Department of Chemistry, College of Natural Science, Chung-Ang University, Seoul 156-756, Korea \\ EE-mail:swham@cau.ac.kr
}

Received March 30, 2010, Accepted May 19, 2010

Key Words: Organogermanium, Antioxidant effects, Vitamin C

Organogermanium compounds have a wide range of biological activities including antimicrobial, antiviral, antineoplastic, analgesic, and immuno-modulating effects. ${ }^{1}$ Among the many organogermaniums known, bis-(carboxyethylgermanium) sesquioxide, which is generally referred to as Ge-132 or 'organic germanium', has been well-studied and is used widely as a dietary supplement. Ge-132 has been reported to enhance several cytokines (such as INF- $\gamma$ and IL-2), which may be due to its antioxidant effects. ${ }^{2,3}$ However, long-term ingestion or high doses of organic Ge-132 can have toxic effects similar to $\mathrm{GeO}_{2}{ }^{4} \mathrm{Ge}-132$ is a water-insoluble polymer that is synthesized from $\mathrm{GeO}_{2}$ and an organic acid. After synthesis and purification, Ge-132 can be contaminated easily with significant amounts of inorganic germanium or other hazardous impurities. ${ }^{5}$ In light of this problem, a novel water-soluble organogermanium compound $(\mathrm{Ge}-\mathrm{OH})$ conjugated with glucose without contamination with toxic inorganic germanium was recently synthesized and found to be a better INF- $\gamma$ inducer than Ge-132. ${ }^{6}$

Regarding the water solubility and antioxidant activity, vitamin C (L-ascorbic acid) was selected as another coupling agent to organogermanium. Vitamin $\mathrm{C}$ is a water-soluble antioxidant. Therefore, it was expected that the antioxidant activity of this conjugated compound would be improved by the combined effects of ascorbic acid and organogermaium. The efficient preparation of organogermanium $\mathbf{8}$ conjugated with ascorbic acid proved to be straightforward. First, commercially available trichlorogermylpropionic acid (1) was converted to trimethylgermylpropionic acid (2) by a treatment with three equivalents of methyl magnesiumiodide according to the literature procedure. ${ }^{7}$ Compound $\mathbf{2}$ was treated with $N$-hydroxysuccinimide (NHS) in the presence of dicyclohexylcarbodiimide (DCC) to produce the corresponding active ester $\mathbf{3}$. The vitamin $\mathrm{C}$ derivative $\mathbf{5}$ was prepared independently from bromide, which was synthesized from ascorbic acid (4) according to the literature procedure. ${ }^{8}$ Preparation of the organogermanium conjugate $\mathbf{8}$ was first attempted by direct condensation between the aminoascorbic acid and compound $\mathbf{3}$, but it was unsuccessful due to the low isolation yield of the amino-ascorbic acid from azide $\mathbf{5}$. To overcome this problem, the hydroxyl groups of compound $\mathbf{5}$ were first protected with benzyl bromide under basic conditions. The resulting compound $\mathbf{6}$ was treated with a solution of triphenyl phosphine in acetonitrile, and then reacted with germylhydroxysuccinimide derivative $\mathbf{3}$ without purification to give the condensation product in $88 \%$ yield. After depro-
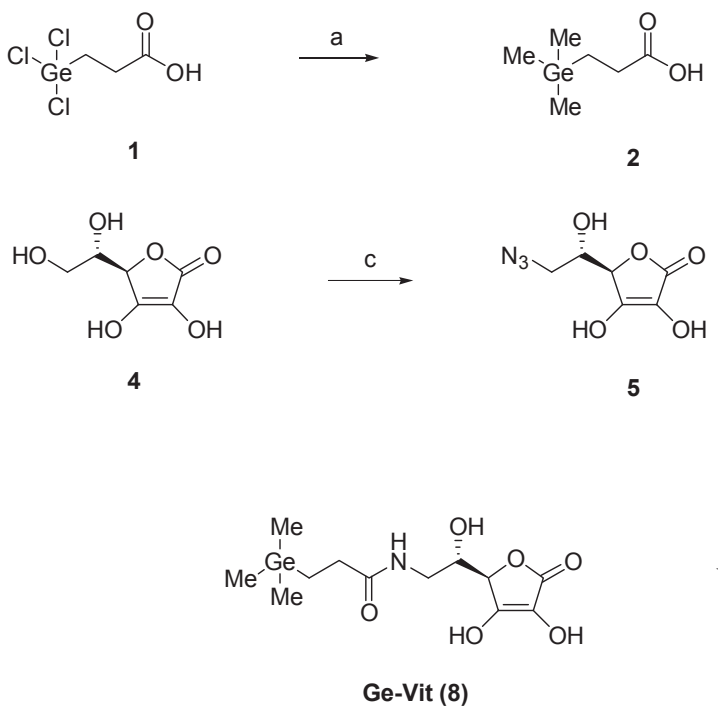
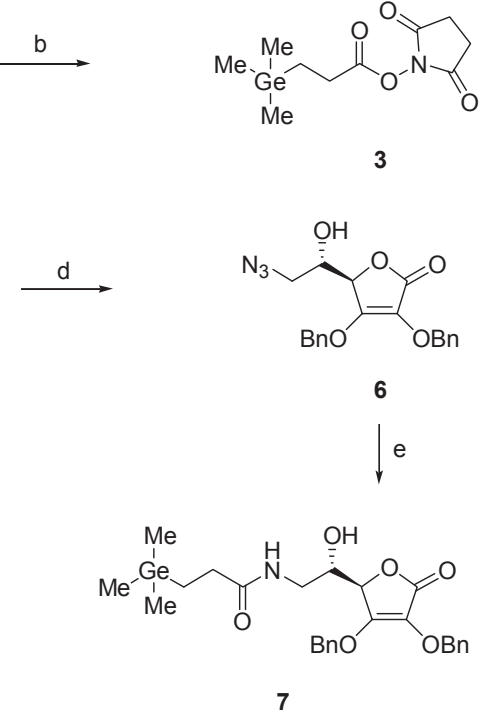

Reagents and Conditions: (a) Ref. 7. (b) DCC, NHS, $\mathrm{CH}_{2} \mathrm{Cl}_{2}, \mathrm{rt}, 16 \mathrm{~h}, 86 \%$. (c) Ref. 8. (d) $\mathrm{Na}_{2} \mathrm{CO}_{3}, \mathrm{BnBr}, \mathrm{DMSO}, 60{ }^{\circ} \mathrm{C}$, overnight, $85 \%$. (e) i) $\mathrm{Ph}_{3} \mathrm{P}, \mathrm{MeCN}, 0{ }^{\circ} \mathrm{C}, 1 \mathrm{~h}$, to $50{ }^{\circ} \mathrm{C}, 2$ h. ii) 3, $\mathrm{MeCN}$, rt, $3 \mathrm{~h}, 88 \%$. (f) $\mathrm{Pd}(\mathrm{OH})_{2}, \mathrm{H}_{2}, \mathrm{MeOH}, \mathrm{rt}, 4 \mathrm{~h}, 86 \%$.

Scheme 1. Synthesis of the water-soluble germanium compound 
tection by hydrogenation in the presence of $\mathrm{Pd}(\mathrm{OH})_{2}$, the resulting crude product was recrystallized in a hexane/ethylacetate solution to produce the final product $(\mathrm{Ge}-\mathrm{Vit}, \mathbf{8})^{9}$ in good yield (Scheme 1).

The free radical scavenging activity of Ge-Vit was then determined using the DPPH (1,1-diphenyl-2-picryl-hydrazyl) assay reported in the literature. ${ }^{10} \mathrm{DPPH}$ is a stable radical with characteristic absorption at $515 \mathrm{~nm}$ due to an unpaired electron. The DPPH radical reacts with compounds with antioxidant activity and is reduced. The reduced form of DPPH is colorless. Therefore, the decrease in $A_{151}$ is considered to be directly related to the electron scavenging capacity of the antioxidant compounds. Accordingly, a freshly prepared ethanolic solution of DPPH $(100 \mu \mathrm{M})$ was incubated at $37^{\circ} \mathrm{C}$ for $30 \mathrm{~min}$ with $10 \mu \mathrm{M}$ aqueous solutions of the compounds at various final concentrations and $\mathrm{A}_{515}$ was measured using a spectrophotometer. As shown in Figure 1, ascorbic acid expectedly showed a high antioxidant activity, but trimethylgermylpropionic acid (2) was not as active as ascorbic acid. On the other hand, the conjugated form of trimethylgermylpropionic acid and ascorbic acid, GeVit, was found to have better antioxidant activity than either ascorbic acid or organogermanium 2 . One reason why Ge-Vit had high antioxidant activity despite the low antioxidant activity of $\mathbf{2}$ is that the liquid trimethylgermylpropionic acid (2) might be too lipophilic to make a homogeneous solution in ethanol for the DPPH assay.

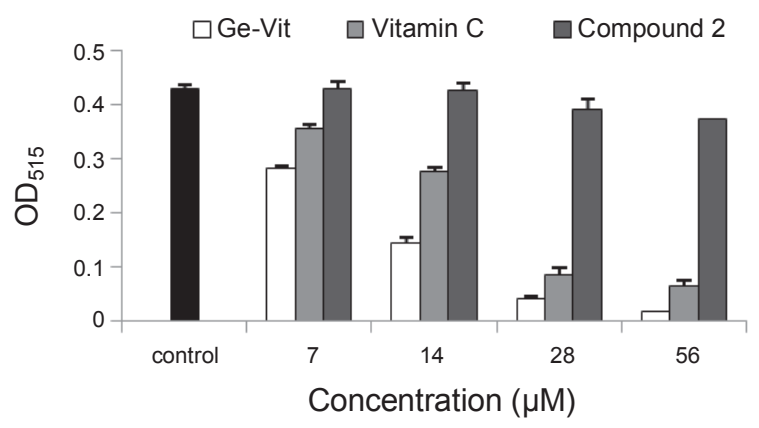

Figure 1

The cumulative amount of ascorbic acid in the cells after permeating through the cell membrane is limited due to its poor liposolubility. Therefore, modification of the hydroxyl groups of ascorbic acid with a lipophilic molecule has been developed to improve its liposolubility. For example, it was reported that synthetic 6-acyl ascorbic acid with fatty acids showed increasing antioxidant potential in skin. ${ }^{11}$ Since Ge-Vit is the conjugated form of ascorbic acid with hydrophobic organogermanium, it is expected that this compound might improve the level of cell penetration. Regarding toxicity of Ge-Vit, when cell viability was measured by the MTT method using HaCaT cells, Ge-Vit showed no effect on it within the given concentration range (up to $50 \mathrm{mM}$ ), suggesting that the compound is not cytotoxic to cells. It was reported that organogermanium enhances INF- $\gamma$ production through its antioxidant effects and high doses of vitamin $\mathrm{C}$ increased the secretion of INF- $\gamma$ in the bronchoalveolar lavage fluid (BALF), suggesting that a supplement of the antioxidant agents might attenuate the inflammation in vivo. ${ }^{12}$ Therefore, it is anticipated that amphiphilic ascorbic acid-conjugated organogermanium would be an useful pharmaceutical material both in vitro and in vivo.

Acknowledgments. This work was supported by the ChungAng University (2010).

\section{References and Notes}

1. Hirayama, C.; Suzuki, H.; Ito, M.; Okumura, M.; Oda, T. J. Gastroenterol. 2003, 38, 525.

2. Brutkiewicz, R. R.; Suzuki, F. In Vivo. 1987, 1, 189.

3. Wakabayashi, Y. Biosci. Biotechnol. Biochem. 2001, 65, 1893.

4. Tao, S. H.; Bolger, P. M. Regul. Toxicol. Pharmacol. 1997, 25 , 211.

5. Kaplan, B. J.; Andrus, G. M.; Parish, W. W. J. Altern. Complement. Med. 2004, 10, 345.

6. Choi, S.; Oh, C.; Han, J.; Park, J.; Choi, J. H.; Min, N. Y.; Lee, K. H.; Park, A. J.; Kim, Y. J.; Jang, S. J.; Lee, D. H.; Ham, S. W. Eur. J. Med. Chem. 2010, 45, 1654.

7. Imafuku, Y.; Takeuchi, Y. Appl. Organometal. Chem. 2004, 18 , 384.

8. Gazivoda, T.; Wittine, K.; Lovric, I.; Kakuc, D.; Plavec, J.; Cetina, M.; Mrvos-Sermek, D.; Suman, L.; Kralj, M.; Pavelic, K.; Mintas, M.; Raic-Malic, S. Carbohyd. Res. 2006, 341, 433.

9. mp $104-105^{\circ} \mathrm{C} .{ }^{1} \mathrm{H}$ NMR $\left(\mathrm{D}_{2} \mathrm{O}, 300 \mathrm{MHz}\right) \delta 0.14(\mathrm{~s}, 9 \mathrm{H}), 0.98$ $(\mathrm{t}, 2 \mathrm{H}), 2.35(\mathrm{t}, 2 \mathrm{H}), 3.53(\mathrm{~m}, 2 \mathrm{H}), 4.13(\mathrm{t}, 1 \mathrm{H}), 4.88(\mathrm{~s}, 1 \mathrm{H}) .{ }^{13} \mathrm{C}$ NMR $\left(\mathrm{D}_{2} \mathrm{O}, 151 \mathrm{MHz}\right) \delta 180.81(\mathrm{~d}, J=5.6), 175.82(\mathrm{~s}), 156.97$ (dd, $J=5.7,1.3), 122.59$ (s), $80.45(\mathrm{~d}, J=150.7), 71.62$ (d, $J=$ $145.1), 46.03(\mathrm{t}, J=139.0), 35.07(\mathrm{tt}, J=127.6), 15.94(\mathrm{t}, J=$ 126.0), $2.73 \sim-4.72(\mathrm{~m}, 3 \mathrm{C})$.

10. Quéléver, G.; Kachidian, P.; Melon, C.; Garino, C.; Laras, Y.; Pietrancosta, N.; Sheha, M.; Louis, K. J. Org. Biomol. Chem. 2005, 3, 2450.

11. Tao, Z.; Ren, Y.; Tong, W.; Wei, D. Pharmacol. Rep. 2005, 57, 77.

12. Chang, H. H.; Chen, C. S.; Lin, J. Y. J. Agric. Food Chem. 2009, 57,10471 . 